\title{
CORPOREIDADE E ENVELHECIMENTO: o significado do corpo na velhice
}

Eliane Jost Blessmann*

\section{Resumo}

Diante de tantas mudanças que ocorrem no corpo com o envelhecimento, e que cada vez o afastam mais do corpo idealizado pela sociedade, cujo valor está no corpo jovem, belo e forte, é que nos questionamos quanto ao significado do corpo na velhice. Na busca de significados o corpo se torna signo, se distingue de um fenômeno que diz respeito a uma composição biológica, e passa a referir-se a um conjunto representativo mental ao qual o sujeito referencia a sua realidade de corpo, e é através do caminho hermenêutico que alcançamos a interpretação.

Palavras-chave: Corpo. Corporeidade. Velhice.

\section{Introdução}

Para falarmos sobre o significado do corpo na velhice é preciso, em primeiro lugar, esclarecer o que é velhice, e conseqüentemente, quem é velho para nós. Velhice é uma etapa da vida, assim como a infância e a adolescência, e velho é quem tem 60 anos ou mais. Porém, dizer que a velhice inicia aos 60 é mero produto de uma definição social. A sociedade estabelece uma idade para o início da velhice em resposta às mudanças evolutivas comuns à maioria das pessoas dos vários grupos etários, considerando os fatores biológicos, históricos e sociais, segundo Neri e Freire (2000). Assim, a Organização das Nações Unidas (ONU) estabeleceu 60 anos para os países em desenvolvimento, e 65 para os países desenvolvidos, tendo como referência a idade para a aposentadoria e a expectativa de vida, que é maior nos países desenvolvidos.

O envelhecimento está, habitualmente, associado às mudanças físicas, tais como, perda de força, diminuição da coordenação e do domínio do

\footnotetext{
* Assistente Social. Especialização em Gerontologia Social da Pontifícia Universidade Católica do Rio Grande do Sul (PUC/RS). Mestrado em Ciências do Movimento Humano - Escola Superior de Educação Física - Universidade Federal do Rio Grande do Sul (UFRGS/ESEF). Email: ejbles.ez@terra.com.br
} 
corpo e deterioração da saúde, e às mudanças cognitivas evocadas por problemas na memória e aquisição de novos conhecimentos, entre outras, omitindo as diferenças individuais e a relação com fatores ambientais e sociais.

No que diz respeito ao corpo, hoje é liberado através do movimento de negação dos tabus repressivos. Imagens do corpo são fartamente disseminadas em jornais, revistas, televisão e anúncios, mas são imagens da juventude, saúde e beleza dos corpos, que se apresentam como ideal a ser alcançado, muito distante da realidade do corpo envelhecido.

Independente de um ideal vivemos um corpo, o corpo é a condição carnal que nos dá acesso ao mundo. E a dinâmica que expressa o modo de ser do homem e que só pode ser compreendida no vivido é a corporeidade, e dela o corpo só emerge pela ajuda da linguagem que o significa.

Temos, de um lado, o corpo natural, que é resultado do processo evolutivo e que corresponde a um ciclo biológico, mediante o qual nascemos, desenvolvemos, adoecemos, envelhecemos e morremos, e de outro, o corpo simbólico que resulta das construções sociais, cuja imagem ideal é a da saúde e beleza associada à juventude.

O significado só pode ser depreendido a partir de uma visão do corpo como signo. O corpo como signo se distingue de um fenômeno que diz respeito a uma composição biológica, fisiológica ou orgânica. Enquanto signo, o corpo não se refere apenas ao corpo presente, mas a um conjunto representativo mental ao qual o comunicante, sujeito de nossa pesquisa, referencia a sua realidade de corpo.

Ao colocarmos o corpo na condição de signo, estamos evidenciando sua presença na linguagem humana como portador de sentido, portanto, passível de interpretação, e então, buscamos o caminho hermenêutico para a sua compreensão.

\section{Contexto Sociocultural da Velhice}

No contexto sociocultural os fatores biológicos ou cronológicos não são critérios para a compreensão da velhice, mas sim o seu significado, a sua simbologia, ou o que ela representa em diferentes épocas. Isto porque, como diz Beauvoir (1990), "[ . . . ] o homem não vive nunca em estado natural; na sua velhice, como em qualquer outra idade, seu estatuto lhe é imposto pela sociedade à qual pertence.” (p. 15). 
A análise feita por Beauvoir quanto a condição dos velhos através do tempo mostra que a contribuição positiva dos idosos para a coletividade é a sua memória e a sua experiência, já que lhes falta a força e a saúde. Quando não havia livros, o velho era o saber acumulado, ele detinha a memória coletiva, evocada e transmitida oralmente, e quanto mais primitiva a sociedade, mais importante era o seu papel.

É possível verificar a associação entre velhice e sabedoria também na descrição das idades da vida, apresentada por Ariès (1981), onde as idades são representadas no século XVI, de acordo com as funções sociais. Em uma pintura no palácio dos Doges, pode ser visto:

Primeiro, a idade dos brinquedos: as crianças brincam com um cavalo de pau, uma boneca, um pequeno moinho ou pássaros amarrados. Depois, a idade da escola: os meninos aprendem a ler ou seguram um livro e um estojo; as meninas aprendem a fiar. Em seguida, as idades do amor ou dos esportes, da corte e da cavalaria: festas, passeios de rapazes e moças, corte de amor, as bodas ou a caçada do mês de maio dos calendários. Em seguida, as idades da guerra e da cavalaria: um homem armado. Finalmente, as idades sedentárias, dos homens da lei, da ciência ou do estudo: o velho sábio barbudo vestido segundo a moda antiga, diante de sua escrivaninha, perto da lareira.

Mesmo não havendo uma unidade no tratamento dispensado aos idosos pela sociedade, pois este sempre variou conforme a época e o local, nas sociedades em que foram exaltados, o que se constata é o domínio social dos mais velhos em relação à apropriação do saber, que se refletia na memória, autoridade e acumulação de bens. Assim, a velhice era reconhecida socialmente, tinha um valor simbólico.

Mas a sabedoria é valor simbólico da velhice somente até o século XIX. Na sociedade moderna predomina a racionalidade e o trabalho produtivo e criativo próprio para os mais jovens, então a velhice passa a ser reconhecida pela decadência física e ausência de papéis sociais. Esta é uma imagem negativa da velhice com a qual convivemos no século XX, pautada sobretudo na fragilidade biopsíquica e na decadência, resultante da perda do status, de poder econômico e social, quando o mundo passa a ser dominado por quem detém a ciência e a técnica, ou seja, os mais jovens.

Atualmente, já se constatam mudanças de atitudes importantes nas diferentes sociedades frente ao envelhecimento, através do reconhecimento de uma série de potencialidades que contribuem para que seja redimensionado o seu lugar social. Do movimento de revisão dos estereótipos associados ao 
envelhecimento, que verifica-se na sociedade contemporânea, resulta uma nova imagem de idoso. Com o aumento da expectativa de vida e das taxas de sobrevida crescem as oportunidades de realização e satisfação do idoso, deixando a velhice de ser caracterizada pelo ócio. Sob a denominação de Terceira Idade impõe-se uma nova ideologia de velhice caracterizada pela atividade, participação e responsabilidade pessoal de cada pessoa envelhecer bem.

\section{Pensando o Corpo e o Envelhecimento}

O dualismo como forma de pensamento influencia a nossa cultura e é base para a própria concepção de mundo, servindo de referência para o sistema de valores no qual se assenta a sociedade. (HIGHWATER, 1992). Pensamos o corpo em oposição à mente, o velho em oposição ao novo, $\mathrm{o}$ idoso ao jovem, o gordo ao magro, a cultura se contrapondo à natureza, e o corpo conhecido em oposição ao corpo vivido.

A mentalidade dualista penetrou tanto no ensino católico como protestante, com isto justifica-se que tenha se evidenciado durante séculos e que permaneça até os dias de hoje. A freqüente alusão à mente jovem e corpo velho é a comprovação da dissociação entre ambos, o que inviabiliza a compreensão da unidade do ser humano. Inclusive eqüivale a pensar o corpo como objeto, como algo fora de si. Se por um lado essa mentalidade dualista permite justificar que a pessoa não se sinta velha mentalmente, espiritualmente, apesar de reconhecer que o corpo está velho, por outro, pode revelar uma forma preconceituosa de conceber a velhice segundo Erbolato (2000), que afirma, "[ . . . ] velhice não é estado de espírito.” (p. 51). De acordo com a autora citada, tratar a velhice como tal é negar as transformações do corpo, o que implica em negar uma parte relevante do próprio idoso.

A visão dualista de homem tem origem na tradição antropológica ocidental, influenciada, segundo Grando (2001), pelas concepções de Platão (430-347 a.C.), "[ . . . ] de que o corpo é o elemento material onde a alma repousa." (p. 63). Daí a idéia de corpo invólucro e de sua pouca importância, expressa até hoje, conforme podemos verificar, o que ratifica a escala hierárquica que exalta a mente e o espírito e denigre o corpo.

O corpo na antigüidade clássica era diminuído ante a mente que formula idéias, a alma que é imortal ou ao espírito que o habita. No corpo 
medieval estão presentes tanto as forças do cristianismo como as concepções pagãs, expressas nos jejuns dos dias santificados e comilança e bebedeira nos demais. O corpo era local de confronto entre o bem e o mal, entre milagre e pecado, entre desejo e castigo, onde as doenças eram consideradas expiação dos pecados cometidos ou possessões diabólicas.

É no Renascimento que o corpo humano começa a se deslocar da carne ao corpo dissecado, descrito em sua anatomia interna e comparado a um mecanismo, com Descartes, onde a doença deixa de ser vista como a manifestação da vontade divina, e sim como um sintoma cuja causa era orgânica. O homem do Renascimento descobriu as belezas do corpo e da natureza, as leis da mecânica e da causalidade tornaram-se o fundamento da ciência e o mundo do sentimento religioso, do irracional e do misticismo, que tivera papel tão importante na época medieval, passou a ser cada vez mais oculto pelos triunfos do pensamento lógico.

O corpo concebido pela lógica cartesiana é pertencente ao domínio da natureza, é puramente material, assim como a mente é puramente razão, princípio que autoriza a razão e a ciência a conhecê-lo e dominá-lo. A teoria cartesiana concebendo o corpo como máquina foi incentivo ético para a Revolução Industrial no Ocidente, segundo Highwater (1992), produzindo um corpo utilitário. Corpo que é manipulado, modelado, treinado, enfim, que se torna hábil e produz.

Na sociedade pós-industrial, caracterizada pela difusão do saber e da informação, por uma tecnologia que ultrapassa a ciência e a máquina para tornar-se social e organizacional, surge uma nova forma de controle, onde o corpo dominado não é apenas o do trabalhador, como antes o foi, afirmam Villaça e Goés (1998). Surgem redes e imagens destinadas a controlar o cidadão consumidor através da produção de serviços e desejos.

A tecnologia investe profundamente nas questões do corpo, identificada com o progresso e a serviço do mercado, que busca se expandir ilimitadamente. Os meios de comunicação de massa atuam no sentido de demonstrar reiteradamente, aos indivíduos, a sua carência de saúde e de beleza, induzindo-os ao consumo de mercadorias e serviços relacionados com as necessidades criadas.

O verbo conjugado pelo capitalismo eu tenho, passou do eu tenho coisas a eu tenho um corpo, à semelhança do que pregava o cristianismo quando dizia que éramos uma alma e tínhamos um corpo. Pensar o corpo nessa perspectiva é recolocá-lo na visão dualista corpo e mente, 
reposicionando-o na escala hierárquica e a ele atribuindo o maior valor. $\mathrm{O}$ apelo a imagem nos afasta da compreensão da unidade do ser humano, eqüivale a pensar o corpo como objeto a ser moldado, como algo fora de si, no mesmo momento em que se inscreve uma nova corporeidade, uma nova maneira de ver o homem. A corporeidade nos permite perceber que o homem é corpo.

O paradigma da corporeidade rompe com o modelo cartesiano, afirma Freitas (1999), deixando de fazer distinção entre a essência e a existência, ou a razão e o sentimento. Sob a ótica da corporeidade

[...] o cérebro não é o órgão da inteligência, mas o corpo todo é inteligente; nem o coração, a sede dos sentimentos, pois o corpo inteiro é sensível. O homem deixou de ter um corpo e passou a ser um corpo. [ . . . ] É como corpo que o homem surge, é também como corpo que ele morre; o que virá a seguir - o céu, o inferno, o nada - não passa de especulação metafísica: o que é certo é que o homem deixará de existir. (FREITAS, 1999, p. 62)

Nietzche (1844-1900) problematizou a condição do corpo que sempre aparecia como objeto, questionando-a, para ele as pessoas deveriam ser inteiramente corpo e mais nada, "[ . . ] s sou todo eu corpo, e nada mais; alma é uma palavra que designa uma parte do corpo." (NIETZCHE, 1974, p. 36). Mas é Merleau-Ponty que procura formular um conceito de corpo não mais orientado pelo dualismo mente-corpo, que o coloca na condição de objeto, mas sim como um modo de ser, modo de se manifestar no mundo, reconhecendo que a presença do homem no mundo é corporal, esta é a sua forma de ser no mundo "[ . . . ] eu não estou diante de meu corpo, estou em meu corpo, ou antes sou meu corpo.” (MERLEAU-PONTY, 1999, p. 208). A idéia de corpo concebida por Merleau-Ponty nos remete a corporeidade.

Viver é assumir a condição carnal de um organismo cujas estruturas, funções e poderes nos dão acesso ao mundo, diz Bernard (1995), e essa condição carnal é ser um corpo. A presença do homem no mundo é corporal. No processo de envelhecimento o corpo assume papel preponderante pois é nele que se dão as mudanças, não só na aparência, como nas suas funções, o que faz com que a velhice seja temida.

A importância do corpo no processo de envelhecimento, segundo Bernard (1995), também pode ser justificada pelo que ele representa. O 
autor chama de ambivalência do corpo o fato dele representar a vida e suas possibilidades infinitas, e ao mesmo tempo, proclamar a morte futura e a finitude existencial. São as duas faces do corpo, de um lado a face dinâmica, ávida de desejos, e de outro, a face da temporalidade, da fragilidade e do desgaste. Em se tratando de envelhecimento implica reconhecer no corpo o potencial e também as limitações da velhice.

Bruhns (2000), coloca a finitude ressaltada por Bernard (1995), juntamente com a visibilidade, como as duas principais características do caráter corpóreo. A visibilidade, segundo a autora, assume grande importância na sociedade contemporânea onde se destaca uma forte ênfase na aparência física e na imagem visual.

Essas características do caráter corpóreo, a finitude e a visibilidade, contribuem significativamente para a rejeição ou o temor da velhice, que podem ser traduzidas pela proximidade do fim ou da morte, e ainda, com uma aparência indesejada.

Cada um tem uma imagem corporal de si mesmo, e esta imagem muda em cada etapa da vida diz Santin (1995). Sendo a velhice considerada uma etapa, assim como a infância e a juventude, é nela que se concentra o momento mais dramático de mudança de imagem corporal, porque é difícil aceitar uma imagem envelhecida em uma sociedade que tem como referência a beleza da juventude.

As referências à juventude, à beleza, à estética, são apenas referências a um corpo objetivo, imagem empobrecida do corpo fenomenal segundo Merleau-Ponty (1999). O corpo definido por Lepargneur (1994) é o que melhor esclarece o corpo fenomenal de Merleau-Ponty, para ele o corpo é "[... ] centro de significações que vem de dentro ou de fora da pessoa." (p. 29). Com isso ele quer dizer que cada indivíduo forma aos poucos uma imagem do próprio corpo, a partir de seus sentimentos de revolta ou de aceitação, compartilhados com a imagem cultural que lhe é transmitida.

Se por um lado, o esquema corporal situa o indivíduo no espaçotempo, e está sujeito a doenças orgânicas, por outro, a imagem de corpo que brota do seu inconsciente, o situa como sujeito de desejo, que aspira a satisfação, e é este o mecanismo que lhe impulsiona. Segundo Santin (1996) o prazer é a palavra que melhor expressa a corporeidade, ele representa todo o processo de busca da complementariedade do corpo, ele é impulsionado pelo desejo, energia que faz com que se viabilize e se operacionalize a atividade corporal. 


\section{Campo da Pesquisa}

A pesquisa foi realizada com o grupo de idosos do Projeto de Extensão da UFRGS, vinculado à Escola de Educação Física, intitulado Centro de Esportes, Lazer e Recreação do Idoso - CELARI, sobre o qual incidiu a nossa observação e com os quais realizamos entrevistas.

\section{O Significado do Corpo na Velhice}

O que define corpo é o seu significado, o fato de ele ser tanto natural como produto da cultura, sua construção que difere para cada pessoa e para cada sociedade, o que vai além das semelhanças biológicas que são universais. Foi sob esta perspectiva que procuramos encontrar o significado de corpo na velhice, no emaranhado de sua complexidade e heterogeneidade, resultante da mútua dependência entre os aspectos biológicos, psicológicos e sociais que interagem no ser humano no processo de envelhecimento como em qualquer outro fenômeno, e que aqui serão tratados como variáveis dentro de um sistema unitário de análise, qual seja, o corpo compreendido como existência.

\subsection{A Dimensão Biológica no Processo de Significação do Corpo na Velhice}

A velhice é inerente ao processo da vida, do mesmo modo que o nascimento, o crescimento, a reprodução e a morte, eventos comuns a todos os seres vivos. Mas nem por isto ela é aceita, e tão pouco justificada, assim como é difícil aceitar a morte. E a velhice acontece no corpo, mas em que corpo se não sabemos defini-lo, se não o conhecemos, se não sabemos ouvilo? É difícil estabelecer se o centro da questão é a velhice ou o é corpo. Mas a certeza está, como diz Beauvoir (1990), em que ela é vivida no corpo, e uma vez que sabemos que a velhice o habita, o corpo, esse estranho, nos inquieta. 


\subsubsection{A Velhice se Revela na Aparência}

"A gente achava que não ia chegar na velhice, mas eu vejo pelo espelho." (sra. I.).

Mesmo que se queira negar a velhice, seus primeiros e mais evidentes sinais se manifestam na aparência, e isto ninguém ignora, de forma que o espelho passa a ser o principal acusador de sua manifestação. A velhice se confirma externamente, através do espelho como elas mesmo disseram, e assim, já não podemos dizer que se trata de uma percepção interior, como muitos gostariam de acreditar.

\subsubsection{O Corpo Físico e Biológico}

"Envelhecendo eu não estou, pode meu corpo estar." (sra. A.).

Com a velhice a aparência do indivíduo se transforma e isto não é fácil de aceitar. A imagem corporal da velhice, é representada pelo declínio físico e visível, e a dificuldade em aceitar este fato induz a existência de um eu visível, que envelhece, e um eu invisível, que se mantém jovem.

\subsubsection{A Visão Mecanicista de Corpo}

"Eu acho que uma pessoa que não se movimenta, um órgão que não funciona pára." (sra. H.).

O corpo sempre foi objeto de atenção e fascinação em toda a história da humanidade, mas nem sempre lhe foi atribuída demasiada importância à aparência, como o é nos tempos atuais. A princípio, o modelo de corpo era fornecido pela ciência dominante, a mecânica, e como conseqüência, o corpo humano era visualizado como máquina, e esta idéia ainda permanece como podemos verificar, é o corpo que não pode parar. A forma como o idoso vê o seu corpo é resquício dessa visão mecanicista. Assim, a cabeça pensa e o corpo age.

\subsubsection{A Funcionalidade do Corpo}

"Mudança que eu senti com o envelhecimento foi as pernas um pouco mais flácidas e tudo o mais, isso ai é o que eu senti." (sra. C.).

Embora não ocorra da mesma forma, nem na mesma época para todas as pessoas, não podemos negar que, a medida que o tempo se impõe, a execução do gesto motor se deprecia, a agilidade diminui, a plasticidade vai se tornando rude, a coordenação vai se tornando alterada pela falta do ritmo e da seqüência natural dos movimentos, e isto passa a ser motivo de 
preocupação. Então, podemos dizer, chega uma hora em que a realidade natural e concreta da velhice é incorporada, e é neste momento que o significado do corpo se volta à funcionalidade. Já não é necessário um corpo belo, mas sim um corpo saudável.

\subsubsection{A Velhice como Sinônimo de Doença}

"Eu sou uma idosa feliz da vida, de bem com a vida, e Deus está me dando esta graça de eu ter saúde até esta idade." (sra. B.).

As doenças são estigmas do envelhecimento. Há uma relação de reciprocidade entre velhice e doença, tão enraizada, que fica difícil lembrar que doença é acidente, e que pode acontecer a qualquer pessoa, em qualquer idade, enquanto a velhice consiste em uma etapa da vida e que só não envelhece quem morre cedo. Mas com a velhice, afirmam muitos autores, $o$ organismo se torna mais suscetível à doença e muitos adoecem, por isso a associação entre velhice e doença. Parece que, ao atingir determinada idade, a pessoa adquire obrigatoriamente doenças, nem lembram que existem pessoas idosas e pessoas idosas doentes. A Sra. B. é um exemplo de velhice sem doença, aos 81 anos de idade.

\subsubsection{A Velhice pode ser Adiada}

"Eu com 66 anos ainda não vi a velhice chegar, em nada, nem no trabalho, nem no corpo, eu não vejo, não é. Também, se eu vejo um cabelo branco já corro para o espelho, agora eu vou fazer tudo de novo, plástica no rosto." (sra. F.).

Os avanços da ciência realimentam o mito da eterna juventude e da imortalidade existente desde a criação da humanidade. Sob a ótica do capitalismo o corpo se apresenta como portador de desejos e deficiências, e o mercado de consumo alcança a velhice disponibilizando produtos e serviços especializados, de forma a induzir que só é velho quem quer. O corpo do idoso, como consumista, está integrado à sociedade, diferentemente, do corpo produtivo da modernidade, para o qual o valor do corpo estava na capacidade de produzir, e o corpo do idoso não era reconhecido como produtor, sendo então, marginalizado.

\subsubsection{A Utopia do Corpo Jovem}

"Do meu corpo já nem sei. Eu tive corpo. Agora eu não tenho, eu nem considero mais.” (sra. J.). 
No mundo das aparências, o corpo envelhecido perde seu significado quando deixa de apresentar as características do corpo jovem, altamente valorizadas na sociedade contemporânea. É como se o corpo perdesse o sentido ou deixasse de existir.

\subsubsection{O Corpo Hierarquicamente Inferior à Mente}

"O corpo tem que ser saudável, e uma mente sã para poder carregar o corpo. É a tua cabeça que vai levar o teu corpo." (sra. B.).

Ao conceberem corpo e cabeça distintamente, estão reproduzindo a condição hierarquicamente inferior a qual o corpo foi historicamente submetido. As freqüentes referências à cabeça e à mente, representam o temor à deterioração intelectual que crêem acompanhar o envelhecimento. A unidade do corpo se dá, nesse caso, em decorrência do reconhecimento de que é necessário preservar as diferentes funções, uma vez que nem todas as pessoas estão condenadas à perda de memória e à redução da capacidade intelectual, assim como não estão condenadas às limitações funcionais.

\subsection{A Dimensão Psicológica no Processo de Significação do Corpo na Velhice}

Para cada pessoa que conhecemos, existe um corpo, e para cada corpo uma cabeça. Isto porque na velhice, para cada pessoa existe um corpo que envelhece e uma cabeça que se mantém jovem. A cabeça é o lugar de resistência e negação da velhice.

\subsubsection{A Velhice como uma Questão de Cabeça}

A cabeça é compreendida como a sede dos pensamentos, das emoções, da identidade, da personalidade e do comportamento, com a idéia de que tudo isso possa ocorrer desvinculadamente do corpo que é gordo ou magro, velho ou jovem, ágil ou lento. Esta situação nos leva a fazer uma distinção entre envelhecimento biológico e envelhecimento psíquico, entre o que acontece no corpo e o que se passa na cabeça, o que não é tão simples, porque não podemos ignorar que exista uma inter-relação entre ambos, e nem mesmo, que cabeça também é corpo.

5.2.1.1 A Cabeça Representa o Centro de Comando: "Velhice é cabeça, então eu não vou ficar velha." (sra. G.). 
Pensamos que velhice como uma questão de cabeça possa estar relacionada ao senso de controle e o que ele representa no envelhecimento. Segundo Goldstein (2000), o senso de controle "[ . . . ] se expressa como a tendência a agir e a sentir-se como alguém que pode influenciar as várias situações da vida" (p. 55), e é importante para a pessoa poder determinar sua vida, manter sua autonomia, por isso a cabeça precisa ser preservada.

5.2.1.2 A Cabeça Representa o Centro da Memória: “A cabeça, nós temos algo dentro que nem os médicos sabem explicar, a gente guarda muita coisa, muitos pensamentos antigos, coisas que nos ocorreram quando criança que hoje a gente não guarda, aconteceu um fato a semana passada eu não me lembro hoje, e me lembro de muitos fatos que aconteceram há 40, 50 anos atrás ... então nós temos, eu acho que nós temos um recipiente no cérebro que guarda isto, então eu procuro preservar o meu cérebro." (sra. A.).

A falta de memória é uma das queixas mais freqüentes entre os idosos. A necessidade de preservação do cérebro, apontada pela sra. A, decorre da necessidade de preservação de suas lembranças, aspectos tão subjetivos, tão próprios da sua particular existência e de tanta importância que, à sua maneira de ver, seria de difícil compreensão para os médicos. Por outro lado, ela parece encarar com naturalidade o esquecimento de fatos recentes. De fato, a memória recente, de curto prazo, diminui com a idade. Já a memória remota, permanece inalterada com o envelhecimento. A memória remota, por ser a responsável pela preservação das lembranças, exerce importante papel na preservação da identidade;

5.2.1.3 A Cabeça Representa a Sede dos Sentimentos: "Seria a minha cabeça, o meu espírito, que eu não me acho velha, não me sinto velha, eu não me vejo assim." (sra. A.).

Ser velho, de acordo com a concepção vigente, é portar estereótipos negativos, o que pressupõe mudanças radicais no comportamento, desde a forma de vestir-se até a maneira de relacionar-se. Quando o idoso não se identifica com os estereótipos de velhice, ele se utiliza do espírito para justificar uma dissociação entre o corpo envelhecido e a sua maneira de viver. Assim, velhice passa a ser estado de espírito. 


\subsubsection{Velhice e Bem-estar Emocional}

"Acho que a gente deve pensar mais na parte de dentro da gente, o que a gente tem na cabeça." (sra. E.).

A aceitação da velhice não como um sentimento, mas como uma etapa da vida, implica em um reposicionamento de seus valores, implica em um voltar-se para dentro de si mesmo. A satisfação com a vida, elemento indispensável ao bem-estar emocional, pode manter-se elevada na velhice, especialmente quando os indivíduos estão empenhados no alcance de metas significativas de vida, que devem ser reformuladas de acordo com novos valores.

\subsubsection{Velhice e Personalidade}

'Eu precisava de alguém que levantasse a minha auto-estima que estava lá em baixo, eu não me sentia mais útil para nada devido às perdas que eu tive." (sra. A.).

A personalidade é um traço humano bastante complexo, ela compreende, entre outros conceitos, a identidade, a auto-imagem, o autoconceito, e a auto-estima. Auto-estimar-se é gostar de si mesmo. É gostar do que realmente é, aceitando suas habilidades e suas limitações. Mas o homem não vive isolado, portanto, para gostar de si mesmo ele precisa do reconhecimento da sociedade, precisa saber se o seu desempenho corresponde às expectativas do outro.

\subsection{A Dimensão Social no Processo de Significação do Corpo na Velhice}

É na dimensão social que melhor se percebe o adiamento da velhice, por ser a mais visível, a que coloca em evidência as mudanças no comportamento das pessoas mais velhas, e com isto tem maior repercussão.

\subsubsection{A Velhice em Outras Épocas}

"Naquele tempo (o da sua infância e adolescência) as pessoas envelheciam muito cedo. A gente via as velhinhas tudo assim, curvadas, então a gente achava que tinham 90 anos, sei lá, tudo assim, ficando dentro de casa, paradinha, tinha velha mais moça que eu (significa com menos de 75 anos." (sra. I.).

Esta é a imagem que a pessoa que hoje está envelhecendo tem de velhice, mas não é assim que ela se vê. A curvatura do corpo é sinal evidente 
de declínio físico, o que não vem ao caso, ela tem o sentido de desuso e conformação com a vida, comuns em outras épocas. Os idosos de hoje não se reconhecem como velhos porque velhice para eles continua sendo inatividade, afastamento e sobriedade.

5.3.2 Idade Cronológica e Aposentadoria como Demarcadores de Velhice "Eu acho que comecei a me sentir velha mesmo foi depois dos 60 anos... depois que eu me aposentei, ai que eu comecei a me sentir velha mesmo. Eu acho que a pessoa que fica mais parada se sente mais velha." (sra. C.).

No contexto sociocultural velhice é uma categoria social e velho continua sendo quem tem 60 anos ou mais. A idade cronológica não leva em consideração as diversidades entre os sujeitos e as experiências de vida, diferentes para cada um. Ela é apenas o tempo de vida, contado a partir do nascimento, mas que serve como demarcador social para o início da velhice. Com igual controvérsia se apresenta a aposentadoria atualmente, que pode ser considerada um marco para o início da velhice e mesmo assim ser vista com satisfação. A aposentadoria se impõe a todos, de forma que um discurso é construído para referendá-la, e as teorias são construídas a partir do que ela representa e das possibilidades de vivê-la de forma satisfatória. Em conseqüência, ela é uma imposição da sociedade e desejada pelos idosos.

\subsubsection{Velhice como Tempo de Mudanças}

"Vou fazer minha atividade na piscina porque preciso extravasar, estou fechando meu escritório, onde só vou pela manhã para ir me acostumando, porque meu sócio está doente e muito mal, quando vou visitar minha mãe que está com 96 anos, vejo que está cada vez mais fraca e não posso fazer nada, chego em casa, não tem ninguém, tinha quatro filhos e agora não tenho nenhum, é duro. Mas já estou fazendo planos, a gente não pode parar. Vão me chamar de louco se eu contar, vou largar tudo e vou viajar." (sr. M.).

Envelhecer implica em mudanças, mudanças na aparência, mudanças nos papéis sociais, mudanças no grupo de amigos e mudanças na vida familiar com a saída dos filhos de casa, por exemplo. E durante muito tempo essas mudanças foram vistas somente como perdas, por ser assim que elas se apresentam. Mas as perdas, em um processo de mudança, implicam também em ganhos, a medida que novas possibilidades vão surgindo. 
5.3.4 A Contribuição das Mulheres para uma Nova Imagem de Velhice

"Eu me sinto bem, e acho assim, dizem que esta é a melhor idade e para mim está sendo. Estou com uma vida muito boa nesta fase, não tenho compromisso, os filhos têm a vida deles, eu tenho liberdade, que é uma coisa que conquistei com o passar dos anos, porque eu trabalhava muito, tinha as crianças pequenas, o marido me incomodava, não deixava sair (agora deixa), eu cheguei na melhor idade, estou numa boa." (sra. F.).

As mulheres são as principais responsáveis pelas mudanças na imagem da velhice, porque livres dos compromissos anteriores, elas passam a desfrutar de outras experiências, das quais até então foram privadas e a velhice para elas se apresenta como um período propício para realizações.

\subsubsection{Uma Nova Imagem de Velhice}

"A minha vida está tão agitada, eu ando correndo tanto, que eu nem tenho tempo para certas coisas. Então eu me sinto feliz porque eu não estou lá pensando em doença, em coisas negativas... o que eu acompanhei com os mais antigos que eu, elas envelheciam dentro de casa, sentadinhas, fazendo tricô, fazendo o serviço de casa, eu achei que eu também fosse chegar assim." (sra. E.).

O mundo está em constante mudança e os velhos também mudam. Hoje, já não se justifica que a velhice implique em afastamento da vida social. Os idosos estão na sociedade, participando mais do que nunca, apenas de outra forma, não mais através do trabalho produtivo e remunerado. As mudanças na velhice são tão radicais que requerem novas denominações, o termo velhice, impregnado de preconceitos, já não dá conta do momento atual, então surge a Terceira Idade. Terceira Idade é o termo que designa atividade e participação.

\section{Considerações Finais}

Investigar sobre o significado do corpo na velhice não foi tarefa fácil, pois as dificuldades se apresentam desde a própria definição dos termos. As pessoas não sabem definir corpo, porque não têm o hábito de fazê-lo, nem de pensá-lo, e também não conseguem definir velhice face à sua heterogeneidade e complexidade, o que é velhice para um, é muito diferente para o outro. Entretanto, uma coisa de comum pode ser depreendida através 
de qualquer explicação que seja tentada para ambos, é a visão biologicizada que se impõe para a sua compreensão. O corpo é compreendido como um conjunto de órgãos e funções, e a velhice, como as alterações que nele ocorrem.

A idéia de velhice, embora um conceito abstrato, é a que nos leva ao corpo, cuja compreensão é muito vaga. Ter idéia de corpo é muito diferente de viver o corpo, como diz Santin (2001-2002), por isso, a maioria dos entrevistados não conseguiu dar uma idéia de corpo, mas falaram da sua experiência de velhice que é vivida no corpo.

É possível identificar três grandes dimensões de velhice e de corpo, tanto nos estudos científicos quanto em pesquisas, daí a nossa opção pela classificação dos depoimentos dos entrevistados, entendendo que cada dimensão fornece um significado para o corpo na velhice.

$\mathrm{Na}$ dimensão biológica a velhice se apresenta como uma dura realidade, vivida num corpo que se transforma e que se torna feio ao desviarse do padrão de beleza vigente na sociedade, corpo que enfraquece e que perde o vigor da juventude, tornando-se mais suscetível a doenças, se comparado às etapas anteriores. É um corpo funcional, na medida em que lhe assegura viver de forma independente.

Na dimensão psicológica a velhice é ainda mais temida diante da ameaça de declínio das capacidades mentais. A cabeça se apresenta como a possibilidade de continuar sendo a mesma pessoa diante das transformações que mudam a sua aparência.

Na dimensão social o significado do corpo na velhice não está no que ele é, mas no que ele representa, ele exalta a vida e suas inúmeras possibilidades, mas ao mesmo tempo proclama a sua finitude existencial.

O homem já foi espírito e alma, em oposição a corpo, o que reservava espaço privilegiado para a velhice que sabia cultivá-lo; já foi razão, abrindo espaço para a modernidade que ressaltou a inteligência e subtraiu o lugar dos velhos, o corpo já foi máquina, a qual se desgasta com o tempo, sugerindo que seja isto que acontece com o corpo envelhecido, e agora ele é mais do que nunca aparência que deve ser conquistada a qualquer custo, e ao mesmo tempo em que, na era da comunicação, ele é o elemento de ligação, então corpo é uma forma de relacionar-se e aí está o espaço reaberto para o corpo na velhice, aquele que engendra relações. 


\title{
CORPORITY AND ODLNESS: the meaning of body in the aging
}

\begin{abstract}
Due to the lot of changes ocurring at the body when it is getting old, what more and more deviates it from the body idealized by the society, in which the value is in a young, beautiful and strong body, it is then when we put into question the meaning of the body in the oldness. Looking for significations the body becomes a sign, distinct from a phenomenonn of biological composition and it is now referred to a mental representativ set to which the person refers his body reality, and it is through in the hermeneutic way that we get the interpretation.

Keywords: Body. Corpority. Oldness.
\end{abstract}

\section{REFERÊNCIAS}

ARIÉS, P. História Social da Criança e da Família. Tradução de Dora Flaksman. 2. ed. Rio de Janeiro: LTC, 1981.

BEAUVOIR, S. A Velhice. Tradução de Maria Helena Franco Monteiro. Rio de Janeiro: Nova Fronteira, 1990.

BERNARD, M. L'approche sociologique: le corps comme structure sociale et mythe. In: . Le Corps. Texto trad. Silvino Santin. Paris: Ed. du Seuil, 1995. Cap. 9, p. 123 - 137.

BRUHNS, H. T. Lazer e Motricidade: dialogando com o conhecimento. In: BRUHNS, H. T.; GUTIERREZ, G. L. (Org.). Temas sobre Lazer. Campinas: Autores Associados, 2000. P. 5-31. (Coleção educação física e esportes). 
ERBOLATO, R. M. P. L. Gostando de Si Mesmo: a auto-estima. In: NERI, A. L.; FREIRE, S. (Org.). E por Falar em Boa Velhice. Campinas: Papirus, 2000. P. 33-54.

FREITAS, G. G. O Esquema Corporal, a Imagem Corporal, a Consciência Corporal e a Corporeidade. Ijuí: UNIJUÍ, 1999.

GOLDSTEIN, L. L. No Comando da Própria Vida: a importância de crenças e comportamentos de controle para o bem-estar na velhice. In: NERI, A. L.; FREIRE, S. A. (Org.). E por Falar em Boa Velhice. Campinas: Papirus, 2000. P. 55-67.

GRANDO, J. C. As Concepções de Corpo no Brasil a Partir de 30. In: GRANDO, J. C. A (des)Construção do Corpo. (Org.). Blumenau: EDIFURB, 2001. P. 61-100.

HIGHWATER, J. Mito e Sexualidade. Tradução de João Alves dos Santos. São Paulo: Saraiva, 1992.

LEPARGNEUR, H. Consciência, Corpo e Mente: psicologia e parapsicologia. Campinas: Papirus, 1994.

MERLEAU-PONTY, M. Fenomenologia da Percepção. Tradução de Carlos Alberto Ribeiro de Moura. 2. ed. São Paulo: Martins Fontes, 1999.

NERI, A. L.; FREIRE, S. A. Apresentação: qual é a idade da velhice? In: . (Org.). E por Falar em Boa Velhice. Campinas: Papirus, 2000. P.

$2-4$.

NIETZSCHE, F. Assim Falava Zaratustra. Tradução de Carlos Grifo Babo. 2. ed. Lisboa: Presença, 1974. 
SANTIN, S. Educação Física: da alegria do lúdico à opressão do rendimento. 2. ed. Porto Alegre: EST/ESEF-UFRGS, 1996.

Educação Física: ética, estética, saúde. Porto Alegre: EST-Escola Superior de Teologia e Espiritualidade Franciscana, 1995.

. O Corpo Simplesmente Corpo. Movimento, Escolax Rendimento, Porto Alegre, n. 15, p. 57-73, 2001-2002.

VILLAÇA, N.; GÓES, F. Em Nome do Corpo. Rio de Janeiro: Rocco, 1998. 